\title{
América en Galdós
}

\author{
CARLOS GARCía BARRón \\ Universidad de Santa Bárbara, California
}

La bibliografía sobre Galdós es, como todos sabemos, extensa, mas hay una importante laguna que no ha sido suficientemente estudiada. Me refiero al análisis del pensamiento de Galdós sobre América ${ }^{1}$. Intentaré en este trabajo trazar el hilo conductor del tema a lo largo de la obra galdosiana para centrarme en uno de sus Episodios nacionales, La vuelta al mundo en la Numancia, donde pienso se refleja con mayor claridad el sentir de don Benito.

En general, el que los españoles se interesasen poco por América en el siglo XIX es comprensible si se tiene en cuenta el antiespañolismo de los países hispanoamericanos tras la guerra de independencia. A ello habrá que sumar los descalabros diplomáticos y militares de los numerosos gobiernos españoles con respecto a América, tales como la anexión de Santo Domingo, la expedición a México de 1862 y el absurdo bombardeo de Valparaíso y El Callao por la flota española en 1866. Son pocas las figuras españolas que manifiestan un interés por lo que

1 Véanse, por ejemplo, estos trabajos: Arturo Capdevila, El pensamiento vivo de Galdós, Buenos Aires, Losada, 1944; Angel del Río, «Notas sobre el tema de América en Galdós,» Nueva Revista de Filología Hispánica, XV (1961), págs. 279-296; El Caballero encantado, ed. Julio Rodríguez-Puertolas, Madrid, Cátedra, 1982 y, finalmente, Brian J. Dendle, Galdós: The Mature Thought, The University Press of Kentucky, 1980. 
sucede en el continente hispanoamericano: Castelar, Menéndez Pelayo, Valera y José María de Labra constituyen la excepción a la regla. Galdós pertenece igualmente a este minoría selecta.

De hecho, América está presente en la obra galdosiana desde el primer momento. Si nos ceñimos a las tres etapas fundamentales en la evolución de su producción literaria, es decir, la naturalista, la de confrontación de materia y espíritu y la extratemporal, veremos que el interés de Galdós por lo americano corresponde a estas tres fases. En la primera don Benito concibe América como parte de la realidad social española. En Gloria nos encontramos con la fortuna de los Lantigua, fortuna procedente de México. Otro caso es el de don Teodoro Golfín, «famoso sabio que ha corrido toda América haciendo maravillosas curas». Así pues, en esta etapa inicial América se asocia a la aventura, al dinero y en menor grado a la ciencia y al progreso. Más adelante, en las novelas de corte realista y naturalista, la visión de América tiende a centrarse en Cuba. A esta isla, parte del Estado español, van a parar los señoritos arruinados con deseos de rehacer su fortuna. La familia de León Roch nos proporciona a Federico Simarra, ejemplo de este tipo de personaje. Hay, claro, muchos otros casos como por ejemplo el de José María, amante de Eloísa en Lo prohibido, o Pedro Minio en La de Bringas, o don Evaristo Feijóo, el protector de Fortunata. En América el español puede abrirse paso, hacerse rico y volver a España como el indiano afortunado. Sobre ello ya existen numerosas alusiones en las novelas del siglo XIX. Apunta al respecto Angel del Río: «Este nuevo caballero se ha liberado, por el trabajo y por el dinero, de la esclavitud a los prejuicios sociales y del falso honor que carcomen a la sociedad española en su atonía» ${ }^{2}$.

Mas será en la cuarta serie de sus Episodios Nacionales donde Galdós reflexione con mayor profundidad acerca de América. En dos de estos Episodios, Prim y La vuelta al mundo en la Numancia, el tema surge con frecuencia. Mas antes de entrar en materia conviene esbozar la índole de esta cuarta serie. García Regalado señala, refiriéndose a la postura de Galdós frente a la sociedad:

La gran sorpresa de la cuarta serie es que el pueblo reaparece, no como la mayoría reaccionaria que antes hemos visto combatiendo por el desconcertante derecho de arrastrar sus cadenas, ni como sector liberal, de triunfo ines-

2 Angel del Río, «Notas sobre el tema...», pág. 285. 
table, forcejeando por defenderse de los ataques del tradicionalismo, sino como la gran masa de todos los vencidos, desheredados y explotados frente a sus opresores, que lo son el tradicionalismo bajo la dirección de la Iglesia, y la burguesía liberal, enriquecida por el desarrollo industrial y la desamortización y representada por una minoría liberal-conservadora, dirigente de la política nacional ${ }^{3}$.

Este viraje en el ideario socio-político de don Benito, por otra parte muy estudiado por muchos galdosistas, coresponde a las fechas en que escribe la Numancia, allá por 1906. Para entonces, Galdós es un decidido republicano, muy consciente de la descomposición nacional agudizada por el desastre de 1898. Apunta en este sentido mi colega Víctor Fuentes:

El ejemplo de Galdós, que a los 64 años de edad y en la cúspide de la gloria literaria, asume la responsabilidad o el compromiso político, sigue siendo, en nuestros días, un ejemplo vivo. Supo ver con lucidez lo que tantos de nuestros grandes escritores españoles y latinoamericanos de este siglo han visto después que él: que en determinada coyuntura histórica la tarea del escritor debe o puede ir más allá de escribir cuentos, novelas, poesías o teatro, aunque también sea importante seguir haciendo esto ${ }^{4}$.

La mínima reacción que suscita en el pueblo español la hecatombe del 98 -que estudié hace años en mi libro Cancionero del $98^{5}$, junto con los infructuosos intentos del Krausismo y del regeneracionismo por hacer mella en la sociedad española, preocupa muy seriamente a Galdós. Sin embargo, en vez de sumarse al pesimismo y catastrofismo imperantes a la sazón, Galdós afirma:

El pesimismo que la España caduca nos predica para prepararnos a un deshonroso morir ha generalizado una idea falsa. La catástrofe del 98 sugiere a muchos la idea de un inmenso bajón de la razón y de su energía... ${ }^{6}$

Don Benito se remonta por encima de la abulia, desidia y actitud negativa del momento y aboga por un futuro esperanzador, visión que incluye no sólo a España sino también a las repúblicas del continente americano. Ya en Prim, Galdós ataca la quijotesca aventura -encarnada

Antonio Regalado García, Don Benito Pérez Galdós y la novela histórica (1862-1912), Madrid, Insula, 1966, pág. 357.

+ Víctor Fuentes, Galdós, demócrata y republicano. Escritos y ensayos (1897-1913) La Laguna, Cabildo Insular, 1982, pág. 46.

Carlos García Barrón, Cancionero del 98, Madrid, Cuadernos para el Diálogo, 1974

6 El Caballero entantado, pág. 33. 
en el joven Santiaguito Ibero- de querer reconquistar la Nueva España, empresa que, afortunadamente, no se lleva a cabo gracias a la oportuna retirada de las fuerzas españolas. Será, sin embargo, en el Episodio citado, La vuelta al mundo en la Numancia, donde Galdós se explaye sobre las relaciones entre España y sus ex-provincias.

El Episodio se basa en la Guerra del Pacífico y es considerado por algunos, como García Regalado, como «uno de los menos interesantes» ${ }^{7}$. En un número reciente de Anales galdosianos publico un artículo en el que se estudian, por primera vez, las fuentes históricas y literarias que utilizó el autor para documentarse ${ }^{8}$. A mi modo de ver, la importancia y originalidad de este Episodio estriba justamente en ser la obra en que Galdós aborda con mayor detenimiento América.

En su reciente libro Galdós: The Mature Thought, el profesor Brian Dendle afirma que don Benito al componer la cuarta serie de episodios trata los hechos históricos en forma muy somera ${ }^{9}$. Mi investigación contradice la aseveración de Dendle, al menos en lo que atañe a la $\mathrm{Nu}$ mancia. En cuanto al interés de Galdós por el Perú, queda ampliamente constatado tanto por su relación epistolar con Ricardo Palma como por los libros sobre ese país que se encuentran en su biblioteca y que había leído con fruición ${ }^{10}$. En todo caso, las propias palabras de Galdós al preparar otro episodio, Amadeo I, parecen refutar la opinión de Dendle: «Ahora estoy preparando el cañamazo, es decir, el tinglado histórico. Una vez abocetado el fondo histórico y político de la novela, inventaré la intriga» ${ }^{11}$. Es evidente pues la enorme importancia que otorga don Benito a la documentación de los Episodios Nacionales. Lo

7 García Regalado, D. Benito Pérez Galdós..., pág. 428.

8 Dendle, Galdos..., pag. 79.

10 Cito a continuación los libros que, a juzgar por sus títulos, versan sobre el Perú: Manuel de Mendiburu, Apuntes históricos del Perú y noticias cronológicas del Cuzco, Lima, Imprenta del estado, 1902; Fernando Valdés Héctor Sierra y Guevara, Conde de Torata, Documentos para la historia de la guerra separatista del Perú, Madrid, Imprenta de la viuda de M. Minusa de los Ríos, 1894-1898; Ricardo Palma, Mis últimas tradiciones, Barcelona, Casa editorial Maucci, 1906; y Ollantay. Drama en verso quechua del tiempo de los Incas, traducido de la lengua quechua al francés y comentado por Gustavo Pachecho Zegarra. Versión española con un prólogo de Pí y Margall, Madrid, Biblioteca universal, 1886.

1 Véase Hans Hinterhauser, Los «Episodios nacionales» de Benito Pérez Galdós, Madrid, Gredos, 1963, pags. 233. 
que sí es cierto es que a partir de la tercera serie, Galdós tiende a condensar el contenido histórico de sus novelas, y cuando no posee algún punto de referencia, como en los capítulos de la Numancia que se desarrollan en el Perú, entonces renuncia intencionadamente a forzar su fantasía, lo que le lleva justamente a apoyarse más en el citado tinglado histórico. Esto lo demuestro claramente en mi artículo sobre las fuentes del episodio.

La Guerra del Pacífico o, mejor dicho, «mini-guerra», ya que su duración fue de unas seis horas, sirve de telón de fondo a este episodio y constituye uno de los más tristes capítulos de la política exterior española del siglo XIX. En mi libro Cancionero de la guerra hispano-peruana de $1866^{12}$ recojo la reacción literaria que provoca dicho suceso en el Perú. Sin entrar en detalles sobre los móviles que impulsaron a España a semejante acción, podemos afirmar sin lugar a equivocarnos que esta expedición militar española fue a todas luces descabellada e inoportuna.

Resumamos ahora brevemente la trama de La vuelta al mundo en la Numancia. El personaje principal es Diego Ansúrez, hombre modesto y marino de profesión. En su juventud había servido en la Armada y recorrido con ella el Pacífico y el Caribe. Retirado, se dedica al comercio de cabotaje. Contrae matrimonio con una ex-monja y de él nace Marina, «Mara», como la llama su padre. Muere la madre, empeoran los negocios de Diego y la niña Mara, convertida en una linda joven, conoce a un peruano, Belisario Chacón, con el que se fuga. De Chacón se nos dice que,

Había nacido al pie de los Andes, sus primeros pasos los dio sobre pavimentos de barras de plata. Su padre era español, que cruzó los mares y se fue en busca de la madre gallega, que así se llama allí a la fortuna. Casó cun una limeña muy guapa... De la dureza del padre y de la propensión del hijo a la independencia, resultaron castigos, rebeldías y sucesos lamentables ${ }^{13}$.

Chacón se escapa a España donde conoce a Mara. Se enamoran y, sin recibir autorización paterna, se fugan. Diego Ansúrez, destrozado y sin medios económicos, opta por enrolarse en la Armada. Una visita a la «Numancia» le convence de la necesidad de reanudar su carre-

12 Carlos García Barrón, Cancionero de la guerra hispano-peruana de 1866, Miami, Ediciones Universal, 1979.

13 Benito Pérez Galdós, La vuelta al mundo en la Numancia, Madrid. Alianza Editorial, 1980, pag. 36. 
ra de marino de guerra. Se convierte así en segundo contramaestre de dicha fragata y hace la travesía en la «Numancia» con la esperanza de poder encontrar a su hija en el Perú. Una vez en Lima se entera de que tanto Mara como su marido - perteneciente a una de las mejores familias limeñas - se han pasado al bando antiespañol. Se produce entonces el conflicto del 2 de mayo de 1866 y el duelo a cañonazos entre la flota española fondeada en El Callao y las baterías peruanas en tierra. Concluido el encuentro bélico, la «Numancia» recibe órdenes de regresar a España. Ansúrez, que no ha logrado dar con su hija, vuelve a la Península en la fragata para, en forma inesperada, encontrarse con ella, su marido y su nieto en España.

Pasemos a continuación a examinar algunos de los juicios sobre América manifestados por Galdós en este episodio. En primer lugar, no vacila en elogiar la entereza y coraje de los marinos españoles, es decir del pueblo español, víctima de la errada política de sus irresponsables gobernantes:

Bien merecían alabanzas los tres mil hombres de mar comprometidos en aquella singular aventura inconsciente, más que empresa meditada. No habían alcanzado aún, ni probablemente alcanzarían, esa gloria brillante y ruidosa que traen consigo los hechos eficaces de finalidad clara y bien comprensible. No se les podía disputar la gloria oscura y pasiva, alcanzada por el valor silencioso y la paciencia, por el cumplimiento del deber, sin más recompensa que la conciencia de haberlo cumplido. Dignos eran de alabanza, y también de lástima, porque sin ver ni aun de lejos los frutos de la campaña, se sentían agobiados de privaciones y sufrimientos. Fueron penitentes en el desierto sin fin de un mar enemigo ${ }^{14}$.

Mendero, viejo amigo de Ansúrez, español afincado en el Perú y casado con una peruana, comenta acerca de las malas relaciones entre España y sus ex-provincias en América. Sus opiniones parecen reflejar el sentir del propio Galdós:

No me meto en si España desenvaina la espada con razón o sin ella. Español trasplantado en América, no entiendo bien de estas cosas y lo que quiero es que la envaine sin deshonor... El que viene de aquel hemisferio a éste, se va dejando en las aguas los puntillos de honra. Cuando uno se establece aquí para ganarse la vida, están muy pasados por agua los orgullos de allá... y esto debe España tenerlo en cuenta antes de sacar de la vaina el espadón... Estos países son hijos del nuestro emancipados, harto grandullones ya para vivir arrimados a las faldas de la madre... y aunque sean algo calaveras, no debe la madre ponerse con ellos demasiado fosca. Son republicanos, han ro-

14 Ibíd., pág. 146. 
to con la historieta vieja, y se traen ellos su historia. España les dio con su sangre la picazón de las rebeldías... debe tratarlos con indulgencia, y no reparar tanto en lo que dicen que de muchachos no debe esperarse mucho comedimiento en la palabra. En fin, éste es mi parecer. Toménlo como quieran, soy español trasplantado, lo que digo es mi pensamiento natural... y algo más que me entra por las raíces ${ }^{15}$.

El mensaje es bien claro. España debe ser una madre comprensiva, consciente de que sus hijas han heredado tanto sus virtudes como sus defectos. Son países nuevos que tienen derecho a forjar su propio destino pero, como jóvenes que son, es preciso tener paciencia con ellos y no castigarlos con excesiva dureza.

Fenelón, el maquinista de la «Numancia», mitad francés, mitad catalán, aporta una visión fría y racional de los hechos. Hombre maduro y curtido por la vida, es capaz de analizar la situación en que se encuentra Ansúrez y aconsejarle lo que debe hacer. Aludiendo al tema que venimos estudiando, declara en una conversación con Ansúrez: «Mara siguió a Belisario deslumbrada por la pasión exuberante de América. América es ya su patria; España, clásica, rígida y enjuta, ya no lo es» ${ }^{16}$.

Fenelón prosigue sosteniendo que el romanticismo puede mucho y que, de hecho, ejerce una enorme influencia:

Romántico fue el amor de tu hija; románticamente te la robó Belisario; al Perú vinieron a realizar sus ensueños; se han casado; son riquísimos... Todo esto quiere decir, por ejemplo, que cuando España arroja de sí el romanticismo, América lo recoge. Los ideales que desechan las madres maduras son recogidos por las hijas tiernas... España coge su rueca, y se pone a hilar el pasado; tu hija hila el porvenir... en rueca de oro ${ }^{17}$.

Lo fundamental aquí no es tanto el énfasis en el papel del romanticismo como la afirmación de que América representa el porvenir, el futuro prometedor, y que ese futuro está en manos de la juventud.

La reconcialización con América es necesaria y urgente, nos indica Galdós, y para conseguir esta difícil meta es preciso basarse en la comprensión y el amor. El hijo de Marta y Belisario representa simbólicamente la unión de ambos mundos, fruto del amor. Tanto el nieto de Ansúrez como el niño Héspero de El Caballero encantado, constituyen

Ibid., pág. 112.

16 Ibíd., pág. 100.

17 Ibíd., pág. 101. 
ese futuro esperanzador y regenerador al que tanto alude Galdós en estas obras de su última etapa.

En 1912, a los seis años de haber escrito la Numancia, afirmaba Galdós:

Esos son países fuertes: la Argentina, Brasil, Chile, el Uruguay; son países jóvenes donde hay vida. Aquí está todo muerto; aquí tiene que haber una gran catástrofe o esto desaparecerá por putrefacción ${ }^{18}$.

En resumen: era ya hora de que España cesara sus «locas aventuras hispánicas» y comenzara a comportarse con sus hijas con comprensión, prudencia, respeto y amor. Había que transformar la sociedad española, caduca y corrupta, aprovechando la savia de las jóvenes repúblicas hispanoamericanas para construir así un futuro mejor para todos. De estos países se podía aprender mucho. Recordemos como punto final las palabras de Diego Ansúrez al reunirse con sus hijos y su nieto en España después de su largo y azaroso periplo: «Lo que he visto y aprendido es que cuando a uno se le pierde el alma tiene que dar la vuelta al mundo para encontrarla» ${ }^{19}$.

El Caballero encantado, pág. 70.

19 La vuelta al mundo en la Numancia; pág. 188. 